\title{
AORTIC VALVE REPLACEMENT AFTER REPAIR OF PULMONARY ATRESIA AND VENTRICULAR SEPTAL DEFECT OR TETRALOGY OF FALLOT
}

\author{
G. Alfred Dodds III, MD \\ Carole A. Warnes, MD, MRCPa \\ Gordon K. Danielson, $\mathrm{MD}^{\mathrm{b}}$
}

\begin{abstract}
Objective: Little attention has been paid to the occurrence of aortic regurgitation after complete repair in patients with pulmonary atresia and ventricular septal defect or tetralogy of Fallot. To highlight the development of aortic regurgitation or aortic root dilation severe enough to necessitate aortic valve replacement with or without aortic aneurysmorrhaphy or aortic root replacement, we retrospectively reviewed the records of patients who underwent aortic valve operation at our institution subsequent to repair of pulmonary atresia and ventricular septal defect or tetralogy of Fallot. Methods: We searched the Mayo Clinic database for patients with pulmonary atresia and ventricular septal defect or tetralogy of Fallot who subsequently had aortic valve or aortic root operations. The degree of aortic regurgitation before operation was noted. Aortic sinus and root dimensions were measured. Results: Sixteen patients underwent complete repair at a median age of 17 years, followed by an aortic operation a median of 13.5 years later. All 16 patients had dilated aortic sinuses at the time of the aortic valve operation. These 16 patients had aortic valve replacement: 11 with mechanical prostheses and 5 with bioprostheses. Five of the 16 also had reduction of aortic dilation by lateral aneurysmorrhaphy, and 1 had graft replacement of the ascending aorta. Five patients had associated conditions (evidence of valvular damage, recurrent ventricular septal defect, or history of endocarditis) discovered at the aortic valve operation that have been reported to be related to the development of aortic regurgitation. The remaining 11 patients had progressive aortic regurgitation despite complete, uncomplicated repair. Conclusions: Progressive aortic regurgitation and aortic root dilation can occur despite complete repair of pulmonary atresia and ventricular septal defect or tetralogy of Fallot. (J Thorac Cardiovasc Surg 1997;113:736-41)
\end{abstract}

A ortic regurgitation is reportedly an uncommon association in patients with pulmonary atresia and ventricular septal defect (PA/VSD) or tetralogy of Fallot (TOF). ${ }^{1-9}$ In patients who do not undergo operation it is progressive and has been attributed primarily to lack of support of the aortic valve cusps, which prolapse into the subaortic VSD. ${ }^{3,8-10}$ In addition, there is often dilation of the aortic anulus

From the Division of Cardiovascular Diseases ${ }^{\mathrm{a}}$ and the Division of Cardiovascular and Thoracic Surgery, ${ }^{\mathrm{b}}$ Mayo Clinic, Rochester, Minn.

Received for publication July 16, 1996; revisions requested Sept. 3, 1996; revisions received Oct. 1, 1996; accepted for publication Oct. 22, 1996.

Address for reprints: Carole A. Warnes, MD, Mayo Clinic, W-16, 200 First St. SW, Rochester, MN 55905.

Copyright @ 1997 by Mosby-Year Book, Inc.

$0022-5223 / 97 \$ 5.00+0 \quad \mathbf{1 2 / 1 / 7 8 7 6 2}$ because the aorta receives most or all of the blood from both ventricles, and this may contribute to aortic regurgitation. Other causes of aortic regurgitation in these patients include a congenitally abnormal aortic valve and damage from endocarditis. ${ }^{2,3,9}$

Although some investigators have noted aortic regurgitation after complete repair, it has usually been mild and of no clinical consequence. $5,10,11$ Indeed, many series have made little mention of aortic regurgitation despite prolonged followup. $^{12-18}$ Late aortic regurgitation has usually been attributed to intraoperative aortic valve damage at repair, aortic valve damage from endocarditis, or recurrent VSD. 3, 4, 7, 19

It is generally accepted, however, that complete repair prevents progression of aortic regurgitation or aortic root dilation. At our institution we encountered patients who subsequently required aortic 
Table I. Summary of clinical data on 16 patients with PA/VSD or TOF and aortic valve operation

\begin{tabular}{|c|c|c|c|c|c|c|c|c|c|c|c|c|}
\hline \multirow[b]{2}{*}{ Patient } & \multirow[b]{2}{*}{ Diagnosis } & \multirow[b]{2}{*}{ Palliation } & \multicolumn{5}{|c|}{ At radical repair } & \multicolumn{5}{|c|}{ At aortic operation } \\
\hline & & & $\begin{array}{l}\text { Age }(y r) / \\
\text { sex }\end{array}$ & $A R$ & $\begin{array}{c}\text { Aortic } \\
\text { sinuses } \\
(m m)\end{array}$ & $\begin{array}{c}\text { Ascending } \\
\text { aorta } \\
(\mathrm{mm})\end{array}$ & $\begin{array}{l}\text { Concomitant } \\
\text { procedures }\end{array}$ & $\begin{array}{l}\text { Age } \\
(y r)\end{array}$ & $A R$ & $\begin{array}{c}\text { Aontic } \\
\text { sinuses } \\
(\mathrm{mm})\end{array}$ & $\begin{array}{l}\text { Ascending } \\
\text { aonta } \\
(\mathrm{mm})\end{array}$ & $\begin{array}{l}\text { Concomitant } \\
\text { procedures }\end{array}$ \\
\hline 1 & $\mathrm{PA} / \mathrm{VSD}$ & B-T shunt & $3 \mathrm{mo} / \mathrm{F}$ & None & 15 & 14 & PDA closure & 24 & Moderate & 46 & 54 & $\begin{array}{l}\text { Redo conduit, } \\
\text { TV repair }\end{array}$ \\
\hline 2 & $\mathrm{PA} / \mathrm{VSD}$ & & $10 / \mathrm{M}$ & Mild & $38^{*}$ & $41^{*}$ & Collateral ligation & 26 & Severe & 44 & 42 & Redo conduit \\
\hline 3 & PA/VSD & AP window & $11 / \mathrm{F}$ & None & 46 & 42 & PDA closure & 15 & Severe & 64 & 52 & Redo conduit \\
\hline 4 & PANSD & & $12 / \mathrm{F}$ & None & 35 & 39 & $\begin{array}{l}\text { PDA closure, } \\
\text { collateral ligation }\end{array}$ & 22 & Moderate & 42 & & $\begin{array}{l}\text { Redo conduit, } \\
\text { aneurysm repair }\end{array}$ \\
\hline 5 & PA/VSD & & $12 / \mathrm{F}$ & None & 32 & 30 & Collateral ligation & 34 & Severe & 51 & 49 & \\
\hline 6 & PA/VSD & & $13 / \mathrm{F}$ & Mild & $37^{*}$ & $39^{*}$ & Collateral ligation & 27 & Moderate & 45 & 47 & $\begin{array}{l}\text { Redo conduit, } \\
\text { aneurysm repair } \\
\text { (collateral ligated } \\
\text { previously) }\end{array}$ \\
\hline 7 & PANSD & & $15 / \mathrm{M}$ & None & 31 & 28 & Collateral ligation & 22 & Moderate & 42 & 38 & Redo conduit \\
\hline 8 & PANSD & & $21 / \mathrm{F}$ & NA & 41 & 45 & PDA closure & 38 & Severe & 42 & 48 & Redo conduit \\
\hline 9 & PA/VSD & Waterston & $22 / \mathrm{M}$ & None & 44 & 45 & $\begin{array}{l}\text { Baffle } \\
\text { TAPVC to LA }\end{array}$ & 36 & Moderate & 53 & 54 & $\begin{array}{l}\text { Redo conduit } \\
\text { TV replacement, } \\
\text { aneurysm repair }\end{array}$ \\
\hline 10 & PANSD & & $25 / \mathrm{M}$ & NA & 42 & 44 & Collateral ligation & 37 & Severe & 51 & & $\begin{array}{l}\text { Redo conduit, } \\
\text { recurrent VSD repair } \\
\text { (collateral coil } \\
\text { closure previously) }\end{array}$ \\
\hline 11 & PAVSD & Potts & $30 / \mathrm{F}$ & None & 46 & 45 & & 43 & Severe & 46 & 59 & $\begin{array}{l}\text { Redo conduit, } \\
\text { aneurysm repair }\end{array}$ \\
\hline 12 & PA/VSD & & $34 / \mathrm{M}$ & Trivial & 52 & & Collateral ligation & 43 & Severe & 63 & 57 & $\begin{array}{l}\text { Redo conduit, } \\
\text { aneurysm repair }\end{array}$ \\
\hline 13 & TOF & & $4 / \mathrm{M}$ & NA & NA & & & 25 & Severe & 81 & & Closure ASD \\
\hline 14 & TOF & B-T shunt & $19 / \mathrm{M}$ & NA & $39^{*}$ & $33^{*}$ & & 47 & Severe & 41 & 39 & $\begin{array}{l}\text { MVR, recurrent } \\
\text { VSD repair (recurrent } \\
\text { VSD repair twice } \\
\text { before AVR) }\end{array}$ \\
\hline 15 & TOF & Potts & $22 / \mathrm{M}$ & NA & NA & & Prior endocarditis & 24 & Severe & 53 & 43 & $\begin{array}{l}\text { Recurrent } \\
\text { VSD repair }\end{array}$ \\
\hline 16 & TOF & $\begin{array}{l}\text { B-T shunt, } \\
\text { Brock }\end{array}$ & $42 / \mathrm{F}$ & Mild & 38 & & & 46 & Moderate & 37 & 33 & $\begin{array}{l}\text { PVR, TV repair, } \\
\text { recurrent VSD } \\
\text { repair }\end{array}$ \\
\hline
\end{tabular}

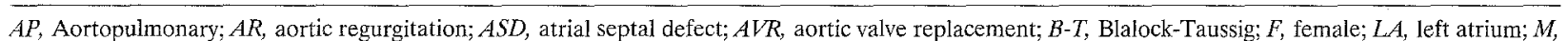
male; $M V R$, mitral valve replacement; $N A$, not available; $P D A$, patent ductus arteriosus; $P V R$, pulmonary valve replacement; $T A P V C$, total anomalous pulmonary venous connection; $T V$, tricuspid valve.

*Data from imaging after repair.

valve replacement despite excellent results after repair. We therefore reviewed our database to identify patients who had aortic valve replacement, aortic root replacement, or ascending aortic aneurysm repair late after repair of PA/VSD or TOF.

\section{Methods}

We reviewed the Mayo Clinic medical records database from 1962 to 1996 for patients with the diagnoses of PA/VSD or TOF who had also undergone aortic valve replacement, aortic root replacement, or ascending aortic aneurysm repair at our institution. Because our aim was to identify the subset of patients who had progressive aortic regurgitation or aortic root dilation after uncomplicated complete repair, we excluded patients who were younger than 14 years old at the time of aortic operation, because the occurrence of aortic operation in the very young implies intervening endocarditis or operative trauma. ${ }^{3,4}$ Sixteen patients were identified; all but 2 (cases 13 and 14, Table I) underwent repair at our institution. Adequate imaging studies of the aortic root before repair were not available in 5 of 16; all 5 (cases 8,10 , and 13 through 15) undenwent repair before 1979. In 2 of these 5 patients, additional imaging studies after repair yet before the aortic operation were available.

The degree of aortic regurgitation was determined from the original cardiac catheterization or echocardiogram report immediately before the operation. Off-line analysis was done for aortic dimensions. Aortic root dimensions 
were measured at the widest point of the sinuses of Valsalva and at the ascending aorta approximately $2 \mathrm{~cm}$ above the sinotubular junction. Echocardiographic measurements were used preferentially over angiographic measurements if both were available. Angiographic measurements were made from cineangiograms or plain radiographic roll film, or both. Interobserver agreement was 96\% for both aortic sinus measurement and for ascending aorta measurement by angiography.

Continuous data were compared with use of the Wilcoxon rank-sum test. Discrete data were compared with the $\chi^{2}$ test.

\section{Results}

Sixteen patients underwent aortic valve operation with or without other procedures on the aortic root at our institution after having had prior complete repair of PA/VSD or TOF (Table I). There were 8 women, and 12 of 16 had PA/VSD. The median age at the time of repair was 13.5 years (range 3 months to 42 years). Only 2 patients were younger than 10 years old at the time of repair. Seven patients had undergone 8 prior palliative procedures.

These patients subsequently underwent aortic valve replacement (10 mechanical prostheses, 5 bioprosthetic valves, and 1 aortic root replacement with a mechanical valved conduit) at a median age of 30.5 years (range 15 to 47 years). The median time from repair to the aortic operation was 13.5 years (range 1 to 28 years). There was a trend toward a longer time to the aortic operation in patients who had repair at a younger age, but this was not statistically significant. Associated procedures in patients with PA/VSD included revision of the right ventricle-pulmonary artery conduit at the time of the aortic valve operation $(n=11)$ and tricuspid valve repair or replacement $(n=2)$. All four patients with TOF had additional procedures at the time of the aortic valve operation (Table I).

The aortic sinus diameter at the time of complete repair (available in 11 patients) was greater than 40 $\mathrm{mm}$ in 6 patients. All 16 patients had aortic sinuses at least $40 \mathrm{~mm}$ in diameter at the time of the aortic valve operation. In 13 , there was specific notation in the operative record of aortic annular dilation. One patient (case 4) had aortic cusp prolapse that was thought to be a result of annular dilation at the time of valve replacement. Five patients (cases 4, 6, 9, 11, and 12) had repair of an ascending aortic aneurysm (47 to $59 \mathrm{~mm}$ diameter at angiography) at the time of the aortic valve operation, three of whom were noted to have cystic medial necrosis on histologic examination of the aortic wall.

Five patients had associated conditions that have been reported to be related to the late development of aortic regurgitation. One patient (case 3 ) had a deformed, near-bicuspid aortic valve with a rudimentary third leaflet. This was evaluated at repair, but the valve was not replaced because there was no aortic regurgitation at preoperative catheterization. A grade $2 / 6$ blowing diastolic murmur was present after operation, and the aortic valve was replaced 3.5 years later. Two patients had evidence of damage to the aortic valve and also had a recurrent VSD. The first (case 15) had a $4 \mathrm{~mm}$ recurrent VSD and a single, $1 \mathrm{~cm}$ hole noted at the base of the noncoronary cusp at aortic valve replacement and also had a history of endocarditis 3 years before repair. This patient had a wide pulse pressure and grade $3 / 6$ diastolic murmur after repair and had the shortest time from repair to the aortic operation in this series ( 15 months). The second patient with evidence of valvular damage (case 14) underwent repair elsewhere at age 19 . Three years later, a recurrent VSD was closed. When seen at our institution at age 29, the patient had a residual VSD and mild aortic regurgitation. At operation, two $2.5 \mathrm{~mm}$ aortic cusp perforations appeared to be a result of suture tears and were closed with a pericardial patch. A $15 \mathrm{~mm}$ recurrent posterior VSD was also patched. No aortic regurgitation was found at examination 6 and 8 years later, though severe aortic regurgitation subsequently developed in this patient. Two other patients had repair of a recurrent VSD at the time of the aortic valve operation. One (case 10) had dehiscence of the VSD patch along the upper third of the suture line; however, no prolapse of the aortic valve was noted at catheterization before operation or at operation. The other patient (case 16) had mild aortic regurgitation on echocardiographic examination before and immediately after repair. At the aortic valve operation she underwent suture closure of a small recurrent VSD. The aortic valve cusps did not prolapse and the aortic regurgitation was not thought to be related to the recurrent VSD.

The remaining 11 patients had complete, uncomplicated repair with no subsequent evidence of valvular damage, recurrent VSD, or history of endocarditis. Five patients had a soft diastolic murmur immediately after repair (cases 1, 4, 7, 9, and 11), but 3 of them had only mild aortic regurgitation at imaging study 4 to 8 years later, and 1 had mild to moderate aortic regurgitation 15 years later. The murmur in the fifth patient (case 7) was attributed to pulmonary regurgitation. A total of 9 patients (cases 
$1,2,4,5,6,8,9,11$, and 12) had a cardiac catheterization, echocardiogram, or both, during the interval from repair to the aortic valve operation that clearly demonstrated a lesser degree of aortic regurgitation than that present at the time of the aortic valve operation, which thus documented the progressive nature of the lesion. By the time of the aortic valve operation ( 7 to 24 years after complete repair), there was specific mention in the operative note of aortic or aortic annular dilation in all 11 patients.

Fig. 1 shows the progression of aortic regurgitation after repair in 11 patients who had an imaging study done to assess aortic regurgitation before repair (see also Table I). At the time of the aortic valve operation in all 16 patients, 9 had severe aortic regurgitation and 7 had moderate aortic regurgitation.

There was only 1 early death in this group, even though 7 patients had undergone palliative operation before repair and all but 2 underwent additional procedures at the time of the aortic valve operation. This patient (case 9) died suddenly in the hospital 6 weeks after a complicated postoperative course after the aortic valve operation. Moderate right ventricular dysfunction had been noted before operation, and at postmortem examination there was severe biventricular hypertrophy with fibrosis and subendocardial infarction of the right ventricle. The death was judged to be caused by multisystem disease and cardiac arrhythmia. The other 15 remain alive a median of 2.5 years (range 0.1 to 17.5 years) after the aortic valve operation. None have had any further aortic operations.

\section{Discussion}

This is the first series that describes progressive aortic regurgitation and aortic root dilation after complete, uncomplicated repair. Other investigators have reported aortic regurgitation or aortic valve operations after repair of PA/VSD or TOF; however, these have generally been isolated cases and progression has not been documented. ${ }^{3,7,11}$ Most have been the result of a recurrent VSD or surgical damage to the aortic valve at the time of initial repair. Although five patients in our series had associated conditions that have been reported to be related to the progression of aortic regurgitation in this population, most of the patients had progressive aortic regurgitation with or without aortic root dilation despite having had successful, uncomplicated repair.

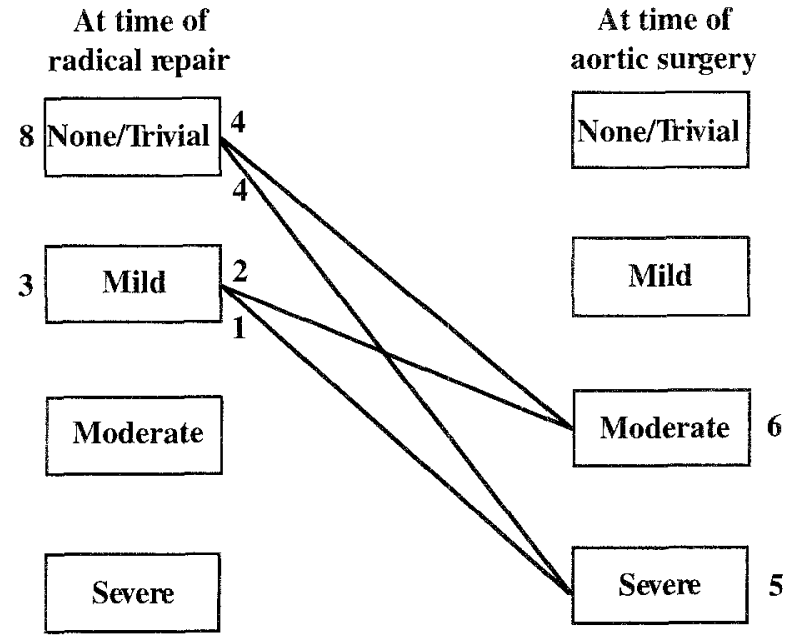

Fig. 1. Progression of aortic regurgitation in patients in whom the degree of aortic regurgitation was determined before complete repair.

Significant aortic regurgitation, when it occurs, appears to take a relatively long time to develop after repair. Presbitero and colleagues ${ }^{4}$ concluded that aortic regurgitation does not progress after intracardiac repair, although the mean follow-up in that series was only 3 years. A series reported by Marelli and colleagues ${ }^{10}$ included 10 patients who underwent repair after age 18 years. Two patients had moderate aortic regurgitation that remained stable after repair (duration of follow-up not specified) and 1 patient had progression from mild to moderate aortic regurgitation over 10 years.

Thus, although progressive aortic regurgitation occurs after repair, the need for aortic valve operation is rare. The reoperation rate after repair in reported series has been $3 \%$ to $24 \%$, with aortic valve operation rare among those who undergo reoperation. ${ }^{12-17}$ Despite the sometimes severe aortic dilation noted in this series and the medial degeneration on histologic examination seen in 3 of the 5 patients who underwent resection of an aneurysmal ascending aorta, no patient had aortic dissection or rupture.

Hemodynamic stress on the aortic wall before repair may play a role in progressive aortic dilation. Marsalese and associates ${ }^{20}$ reported on 93 patients (none with congenital heart disease) with medial degeneration diagnosed after aortic operation or at autopsy. Aortic regurgitation was seen in $72 \%$ of their patients who underwent catheterization and aortic dilation was seen in $78 \%$. The association of severe aortic regurgitation and its resultant hemo- 
dynamic stress with aortic dilation and medial degeneration has been noted by others. ${ }^{21,} 22$ In addition, patients with bicuspid aortic valves also have progressive aortic root dilation and often have medial degeneration of the aorta. ${ }^{22,23}$

In these patients, however, aortic regurgitation seems to be the result of, rather than the cause of, progressive aortic root dilation. Indeed, we recently saw a patient who had aortic valve replacement at the time of complete repair at age 43 and subsequently had progressive aortic root dilation to $85 \mathrm{~mm}$, necessitating cardiac transplantation despite the absence of aortic regurgitation. We believe it is unlikely that patients with PA/VSD or TOF have an intrinsic abnormality of the aortic wall as has been postulated for patients with bicuspid aortic valves. ${ }^{22,23}$ Rather, we agree with others that the aortic wall is damaged from years of increased flow before repair. ${ }^{11,24}$ If increased flow through the aorta is a major contributor to aortic annular and ascending aortic dilation, this complication should be more common in patients who were older at repair and in those with PA/VSD as compared with TOF. This is suggested in our series in which only 2 patients were younger than 10 years old at the time of repair and 12 of the 16 patients had PA/VSD with its attendant greater flow through the aorta compared with TOF.

Why the aortic dilation should progress, however, remains unclear. It seems likely that the early hemodynamic stress on the aortic wall induces the medial damage. This would be analogous to the medial degeneration seen in patients with long-standing aortic regurgitation. ${ }^{20}$ The medial damage might then provide the substrate for further dilation and regurgitation. We have no direct evidence that our patients had medial degeneration at the time of repair.

Limitations. It is possible that a bias exists for patients with long-term complications being referred back to our institution for follow-up. Because of the referral nature of our patient population, we may encounter this late, uncommon complication with unusual frequency. In addition, the advent of two-dimensional and color-flow Doppler echocardiography may in part account for an increased awareness of this complication.

This study was retrospective, and the limitations of measuring aortic dimensions from imaging studies not specifically directed at the regions of interest must be noted.

We excluded patients younger than 14 years old. This cutoff is arbitrary but was based on the belief that the development of aortic regurgitation before the teenage years in those who have had repair suggests other complicating factors. ${ }^{3,4}$

Conclusions. Progressive aortic dilation or aortic regurgitation, or both, occurs after complete repair in patients with PA/VSD and to a lesser extent in those with TOF. This deterioration may take a long time to develop and therefore warrants continued observation of these patients after repair. Aortic regurgitation should be carefully sought by auscultation, but it may be difficult to delineate in the setting of prosthetic pulmonary valve regurgitation or residual collaterals. This emphasizes the need for a comprehensive transthoracic two-dimensional and Doppler echocardiogram not only to quantitate the degree of aortic regurgitation but also to evaluate the size of the ascending aorta. Other imaging modalities such as computed tomography, magnetic resonance imaging, or angiography should be considered if there is clinical suspicion of aortic dilation. These observations emphasize the need for continued and life-long follow-up of all patients after repair of PA/VSD and TOF.

\section{REFERENCES}

1. Nagao GI, Daoud GI, McAdams AJ, Schwartz DC, Kaplan S. Cardiovascular anomalies associated with tetralogy of Fallot. Am J Cardiol 1967;20:206-15.

2. Glancy DL, Morrow AG, Roberts WC. Malformations of the aortic valve in patients with the tetralogy of Fallot. Am Heart J 1968;76:755-9.

3. Capelli H, Ross D, Somerville J. Aortic regurgitation in tetrad of Fallot and pulmonary atresia. Am J Cardiol 1982; 49:1979-83.

4. Presbitero P, Demarie D, Aruta E, et al. Results of total correction of tetralogy of Fallot performed in adults. Ann Thorac Surg 1988;46:297-301.

5. Zahka KG, Horneffer PJ, Rowe SA, et al. Long-term valvular function after total repair of tetralogy of Fallot: relation to ventricular arrhythmias. Circulation 1988;78(Suppl):III14-9.

6. Puga FJ, Leoni FE, Julsrud PR, Mair DD. Complete repair of pulmonary atresia, ventricular septal defect, and severe peripheral arborization abnormalities of the central pulmonary arteries: experience with preliminary unifocalization procedures in 38 patients. I Thorac Cardiovasc Surg 1989;98: 1018-29.

7. Bilfinger TV, Seifert FC, Vallone AM, Biancaniello TM. Aortic valve injury 10 years after tetralogy of Fallot repair. Pediatr Cardiol 1994;15:100-2.

8. Bull K, Somerville J, Ty E, Spiegelhalter D. Presentation and attrition in complex pulmonary atresia. $\mathbf{J}$ Am Coll Cardiol 1995;25:491-9.

9. Matsuda H, Ihara K, Mori T, Kitamura S, Awashima Y. Tetralogy of Fallot associated with aortic insufficiency. Ann Thorac Surg 1980;29:529-33.

10. Marelli AJ, Perloff JK, Child JS, Laks H. Pulmonary atresia with ventricular septal defect in adults. Circulation 1994;89: 243-51. 
11. Rieker RP, Berman MA, Stansel HC. Postoperative studies in patients with tetralogy of Fallot. Ann Thorac Surg 1975; 19:17-26.

12. Murphy JG, Gersh BJ, Mair DM, et al. Long-term outcome in patients undergoing surgical repair of tetralogy of Fallot. N Engl J Med 1993;329:593-9.

13. Garson A, Nihill MR, McNamara DG, Cooley DA. Status of the adult and adolescent after repair of tetralogy of Fallot. Circulation 1979;59:1232-40.

14. Fuster V, McGoon DC, Kennedy MA, Ritter DG, Kirklin JW. Long-term evaluation (12 to 22 years) of open heart surgery for tetralogy of Fallot. Am J Cardiol 1980;46:635-42.

15. Walsh EP, Rockenmacher S, Keane JF, Hougen TJ, Locke JE, Castaneda AR. Late results in patients with tetralogy of Fallot repaired during infancy. Circulation 1988;77:1062-7.

16. Kirklin JW, Blackstone EH, Shimazaki Y, et al. Survival, junctional status, and reoperations after repair of tetralogy of Fallot with pulmonary atresia. J Thorac Cardiovasc Surg 1988;96:102-16.

17. Pome G, Rossi C, Colucci V, et al. Late reoperations after repair of tetralogy of Fallot. Eur J Cardiothorac Surg 1992; $6: 31-5$.

18. Waien SA, Liu PP, Ross BL, Williams WG, Webb GD,
McLaughlin PR. Serial follow-up of adults with repaired tetralogy of Fallot. J Am Coll Cardiol 1992;20:295-300.

19. Uretzky G, Puga FJ, Danielson GK, Hagler DJ, McGoon DC. Reoperation after correction of tetralogy of Fallot. Circulation 1982;66(Suppl):I202-8.

20. Marsalese DL, Moodie DS, Lytle BW, et al. Cystic medial necrosis of the aorta in patients without Marfans syndrome: surgical outcome and long-term follow-up. J Am Coll Cardiol 1990;16:68-73.

21. Roman MJ, Devereux RB, Niles NW, et al. Aortic root dilatation as a cause of isolated, severe aortic regurgitation: prevalence, clinical and echocardiographic patterns, and relation to left ventricular hypertrophy and function. Ann Intern Med 1987;106:800-7.

22. Hahn RT, Roman MJ, Mogtader AH, Devereux RB. Association of aortic dilatation with regurgitant, stenotic and functionally normal bicuspid aortic valves. J Am Coll Cardiol 1992;19:283-8.

23. Lindsay J. Coarctation of the aorta, bicuspid aortic valve and abnormal ascending aortic wall. Am J Cardiol 1988;61:182-4.

24. Fyler DC. Tetralogy of Fallot. In: Fyler DC, ed. Nadas pediatric cardiology. 1st ed. Philadelphia: Hanley and Belfus, 1992:471-91. 